\title{
COMPARATIVE STUDY OF EFFICACY OF MEDICAL (TAMSULOSIN+DUTASTERIDE) WITH SURGICAL (TURP) MANAGEMENT IN BENIGN PROSTATIC HYPERPLASIA
}

\author{
R. G. Naniwadekar ${ }^{1}$, Sangeeta Biradar ${ }^{2}$, Jignesh Savsaviya ${ }^{3}$, Basvaraj Nagur ${ }^{4}$, Raunak Chabara 5 , Neha Sawant 6
}

1 Professor, Department of Surgery, Krishna Institute of Medical Sciences Deemed University, Karad.

${ }^{2}$ Resident, Department of Surgery, Krishna Institute of Medical Sciences Deemed University, Karad. ${ }^{3}$ Resident, Department of Surgery, Krishna Institute of Medical Sciences Deemed University, Karad. ${ }^{4}$ Resident, Department of Surgery, Krishna Institute of Medical Sciences Deemed University, Karad. ${ }^{5}$ Resident, Department of Surgery, Krishna Institute of Medical Sciences Deemed University, Karad. ${ }^{6}$ Resident, Department of Surgery, Krishna Institute of Medical Sciences Deemed University, Karad.

\section{ABSTRACT}

Benign Prostatic Hyperplasia (BPH) is one of the most common diseases of the aging men. It is associated with bothersome Lower Urinary Tract Symptoms (LUTS). With age the prostate gland either atrophies or hypertrophies producing various types of bladder outlet symptoms in a significant number of cases.

\section{OBJECTIVES}

To study the patient of BPH, which are suitable for medical line of treatment with surgical line of treatment. To study the outcome of medical management with surgical management.

\section{METHODS}

Between December 2013 and July 2015 we studied 100 men, age group of above 50 years, who were attending the Outpatient Department of Surgery at Krishna Institute of Medical Sciences, Karad. Patients underwent a complete history taking and physical examination.

\section{CONCLUSION}

Benign Prostatic Hyperplasia (BPH) is a common cause of Lower Urinary Tract Symptoms (LUTS) in men over 50 years of age and can have a significant impact on the quality of life of BPH patients.

\section{KEYWORDS}

Benign Prostatic Hyperplasia, TURP, Dutasteride, Tamsulosin.

HOW TO CITE THIS ARTICLE: Naniwadekar RG, Biradar S, Savsaviya J, et al. Comparative study of efficacy of medical (tamsulosin+dutasteride) with surgical (TURP) management in benign prostatic hyperplasia. J. Evolution Med. Dent. Sci. 2016;5 (68): 4861-4863, DOI: $10.14260 /$ jemds/2016/1105

\section{INTRODUCTION}

Benign Prostatic Hyperplasia (BPH) is one of the most common diseases of the aging men. It is associated with bothersome Lower Urinary Tract Symptoms (LUTS). With age the prostate gland either atrophies or hypertrophies producing various types of bladder outlet symptoms in a significant number of cases.

\section{METHODS}

Between December 2013 and July 2015 we studied 100 men, age group of above 50 years, who were attending the Outpatient Department of Surgery at Krishna Institute of Medical Sciences, Karad; 50 patients were offered medical treatment and 50 were offered surgical treatment. Men assigned to both the groups were similar in terms of age and associated illness. The baseline IPSS scores in the medical management group were in majority moderate range for all patients, while those in surgical group were both in moderate and severe range.

Financial or Other, Competing Interest: None.

Submission 10-04-2016, Peer Review 11-08-2016,

Acceptance 17-08-2016, Published 23-08-2016.

Corresponding Author:

Dr. Sangeeta Biradar,

Room No. 31, IHR PG Hostel,

Krishna Institute of Medical Sciences

Deemed University,

Karad.

E-mail: arukadam411@gmail.com

DOI: $10.14260 /$ jemds/2016/1105
Patients underwent a complete history taking and physical examination including neurological examination, especially in diabetic patients to rule out any evidence of diabetic neuropathy. The men's symptoms were assessed by International Prostatic Symptom Score (IPSS). Enlarged prostate was confirmed on digital rectal examination, which was further confirmed by 'transabdominal ultrasonography.'

\section{RESULTS}

\begin{tabular}{|c|c|c|}
\hline Incidence (In Year) & Medical & Surgical \\
\hline $51-60$ & 9 & 3 \\
\hline $61-70$ & 23 & 27 \\
\hline $61-80$ & 14 & 17 \\
\hline$>80$ & 4 & 3 \\
\hline \multicolumn{2}{|c|}{ Table 1: Age Distribution } \\
\hline
\end{tabular}

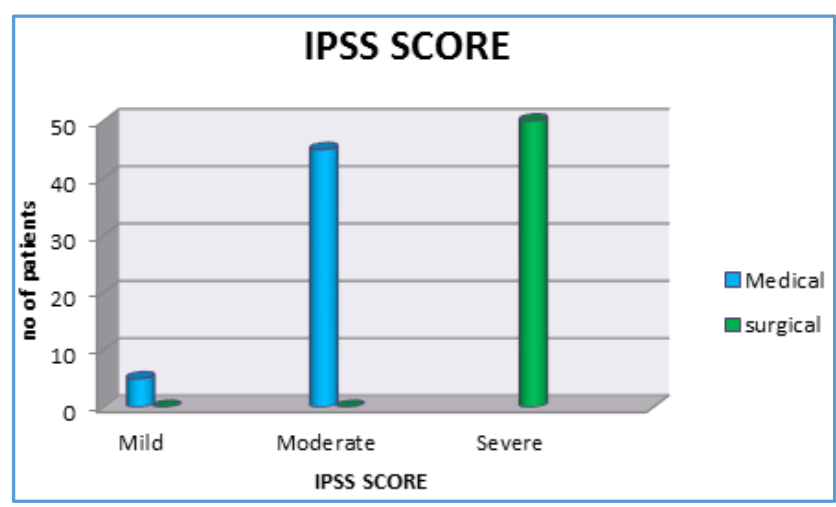


IPSS Score Follow-up over 12 Months

\begin{tabular}{|c|c|c|}
\hline Duration Follow-Up & Medical & Surgical \\
\hline Baseline & $11.82 \pm 1.54$ & $22.32 \pm 1.77$ \\
\hline 3 months & $9.96 \pm 1.41$ & $4.5 \pm 0.86$ \\
\hline 6 months & $8.22 \pm 1.37$ & $3.26 \pm 0.69$ \\
\hline 9 months & $6.68 \pm 1.16$ & $2.82 \pm 0.69$ \\
\hline 12 months & $5.3 \pm 0.76$ & $2.42 \pm 0.53$ \\
\hline
\end{tabular}

\section{DISCUSSION}

\section{Age Distribution}

There is no difference in the age group in the medical and surgical group. Most of the patients are in the age group of 60 70 years. Average age group in our study was 70 years. There was no patient below the age of 50 years. Youngest patient in our study group was 52 years and oldest was 90 years. These above findings confirm those of the Schwartz study, who has shown that symptomatic BPH is rare before the age of 40 years. ${ }^{1}$

Lepor $\mathrm{H}$ et $\mathrm{al}^{2}$ in 1989 , reported in their study on the efficacy and safety of medical management in the treatment of $\mathrm{BPH}$ that the mean age of patients was $63.9 \pm 1.0$. A similar study by Lepor H, Ridaud G3 in 1991) on efficacy of TURP in men with BPH, reported that the mean age of patients was $66.6 \pm 1.2$.

In our study the mean age of patients in medical treatment group was $67.98 \pm 7.72$, and the mean age in surgical treatment group was $68.48 \pm 7.99$.

\section{IPSS Score}

In our study group out of 100 cases 50 patients (50\%) presented with severe grade of (19-35), 45 patients (45\%) presented with moderate score of (8-19) and 5 with mild symptoms.

It indicates that there is no correlation between the age of the patient and A.U.A symptom score. In our study most common symptom is of weak stream, second most common is staining for micturition followed by increased frequency and overflow incontinence is least common.

\section{Follow-Up over 12 Months}

Improvement in the IPSS score at the end of therapy at 12 months in the medical group is $55 \%$ and the surgical group is 89\%. Decrease in IPSS after therapy during follow-up at the end of the treatment at 12 months follow-up in medical group is 6.5 and in surgical group is 19.9.

\section{Volume of Prostate}

The average volume of the prostate gland as obtained by transabdominal USG was 56 grams. The smallest prostate gland has a weight of 29 grams and the largest was of 98 grams.

In our study the average volume of the prostate for age group 50-60 years was $56 \mathrm{~cm}$, while it was $70 \mathrm{~cm}$ for the age group 61-70 years. The volume for 71-80 years was $66 \mathrm{~cm}$. But for more than 80 years, it was decreased to $45 \mathrm{~cm}$. This suggests that there was no correlation between age and prostate volume.

These findings coincide with those of Mukendo Kojima et $\mathrm{al}^{4}{ }^{4}$ who demonstrated that there was no significant linear correlation between age and prostate volume.

Out of 100 patients given treatment on transabdominal USG showed mainly median lobe enlargement $48 \%$ and $47 \%$ showed trilobular enlargement of prostate and remaining $5 \%$ fibrous prostate.

\section{A.U.A Score: (IPSS)}

In our study group out of 100 cases 50 patients (50\%) presented with severe grade of (that is between 19-35), 45 patients (45\%) presented with moderate score (8-19) and 5 with mild symptoms. It indicates that there is no correlation between the age of the patient and A.U.A symptom score.

\section{Complications of BPH}

In the American Urological Association Cooperative Study in $1989,70 \%$ of patients had more than one indication for surgery; $27 \%$ of patients had acute urinary retention, $12.3 \%$ bad recurrent urinary tract infection and 3\% had bladder stones.

McConnell et al 5 in 1994 reported that 20 to $30 \%$ of men undergoing prostate surgery have urinary retention and 1 to $2 \%$ of them have concomitant bladder stones.

In our study $7(14 \%)$ cases had reported with acute retention of urine, 4 (8\%) cases had complications of treatment.

\section{Transurethral Resection Syndrome or Dilutional Hyponatraemia}

In AUA cooperative study (Mebust et al 1989), TUR syndrome occurred in $2 \%$ of patient's TUR syndrome is an alteration in homeostasis produced by extravasation due to the perforation of capsule and intravasation due to the sucking in of irrigation fluid in the venous sinuses. None of the patients developed symptoms.

\section{Incontinence of Urine}

Incontinence after operation on prostate arises after varying degree of trauma to external sphincter.

In our study group, permanent incontinence has not occurred to any of the patients. Two of our, i.e. $4 \%$ patient developed incontinence temporary for 5-6 days after removal of catheter. The patient become continent after 3-4 days.

The co-operative study conducted by A.U.A permanent incontinence after TURP is $0.5 \%$ of patient. ${ }^{6}$

\section{Post-Operative Urinary Tract Infection}

UTI occurs after TURP due to prolonged catheterisation. In our study group, 2 patient (4\%) had post-op urinary tract infection. In a co-operative study conducted by AUA incidence of UTI after TURP was $25 \%$.

A positive correlation between incidence of urinary tract infection and post-operative catheterisation was established by Jackman Chisholm and G.D. ${ }^{7}$

\section{Urethral Catheterisation}

Urethral catheterisation is must after surgery for BPH. Prolonged catheterisation leads to increased morbidity of patient. In our study, most of the patients required catheterisation for 3-5 days.

In Rob and Smith's operative, it has been stated that urethral catheterisation after TURP can be safely removed after 2-3 days if urine is clear. ${ }^{8}$

The mortality rate has decreased significantly following TURP over the past three decades. In our study, there was no mortality. In most series, the early mortality rate for TURP is $0.02 \%$.

Combination Therapy: Tamsulosin $0.4 \mathrm{mg}$ and dutasteride $0.5 \mathrm{mg}$ is used in combination therapy has advantage of it 
reduces IPSS score, prostate volume, increases the urinary flow rate, decreases the rate of acute retention of urine and prostatic surgery.

In our study group mean decrease in the IPSS score was 6.5 i.e. $55 \%$ in medical therapy and 19.9 i.e. $89 \%$ improvement in surgical patient.

The complications in our study group in combination therapy were retrograde ejaculation $4 \%$, loss of libido $4 \%$ and gynaecomastia is $2 \%$.

Discontinuation of therapy was due to retrograde ejaculation and gynaecomastia, which was $6 \%$. They had opted surgical procedure.

It is also a well-known fact that prostatic cancer often coexists with $\mathrm{BPH}$, hence one disadvantage of medical therapy is lack of tissue for histopathological examination, whereas in TURP we are obtaining tissue which is routinely sent for histopathological studies so that incidental cases of prostatic cancer can be detected.

\section{CONCLUSIONS}

Benign Prostatic Hyperplasia (BPH) is a common cause of Lower Urinary Tract Symptoms (LUTS) in men over 50 years of age and can have a significant impact on the quality of life of BPH patients.

The treatment of clinical BPH is targeted to improve symptoms of prostatism, relieve obstruction, improve bladder emptying and prevent urinary tract infection and renal function deterioration. The treatment option of BPH has drastically changed over the last decade owing to altered perception of the natural history and pathophysiology of the disease process.

Prostatectomy resects the obstructing tissue. Medical therapies are targeted to relieve obstruction by relaxing smooth muscle (Alpha-Blockers) or promoting regression of the disease process (Androgen Ablation).

We thus conclude the medical treatment should be offered to those patients who are not willing for surgery, are unfit for surgery or having early symptoms of prostatism. In spite of the associated post-operative morbidity in a few elderly patients after surgery, of all treatment options prostate surgery offers the best chance of symptom improvement with TURP being the gold standard procedure. Surgical excision has been the cornerstone in the management of BPH for nearly a century.

\section{REFERENCES}

1. Abbou CC, Salmon L, Chopin D. The current approach to management of benign hypertrophy of prostate. Ann Urol (paris) France 1996;30(6-\&):294-299.

2. Lepor H, Knapp-Maloney G, Wozniak-Petrofsky. The safety and efficacy of terazosin for the treatment of benign prostatic obstruction. Int J Clin Pharmacol Ther Toxicol 1989;27:392-397.

3. Lepor H, Rigaud G. The efficacy of transurethral resection of the prostate in men with moderate symptoms of prostatism. J Urol 1990;143(3):533-537.

4. Kojima M, Naya Y, Inoue W, et al. The American urological association symptom index for BPH as function of age, volume and ultrasonic appearance of prostate. J Urol 1997;157(6):2160-2165.

5. Mc Connell JD, Barry Mi. Bruskewitz RC, et al. Benign prostatic hyperplasia: diagnosis and treatment. Clinical Practise Guidelines. No. 8, AHCPR Publication No 94-0582. Rockville, MD: Agency for Health Care Policy and Research, Public Health Service, US Department of Health and Human Services 1994.

6. Mebust WK, Holtgrewe HL. Current status of transurethral prostatectomy: a review of the AUA National Study. World J Urol 1989;6(4):194-197.

7. Jackman FR, Chisholm GD. Urinary infection and prostatectomy. British Journal of Urology 1957;47:545549.

8. Whitefield HN. Rob and Smith's operative surgery, Genitourinary surgery. Endoscopic procedures. $5^{\text {th }}$ edn Oxford: Butterworth-Heinemamn 1993:144-145. 